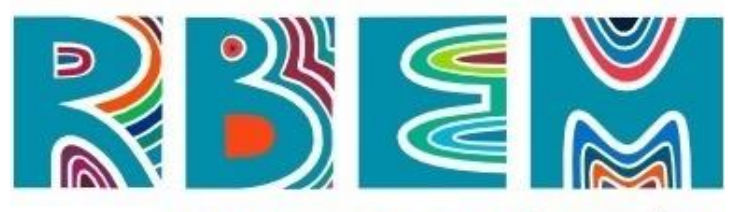

\title{
ARTIGO
}

do1 https://doi.org/10.47207/rbem.v2i01.12132

\section{Conhecimentos e aprendizagens produzidas e mobilizadas por futuros professores em uma disciplina de Estágio - Possibilidades no Contexto Pandêmico}

\author{
MARTINS, Priscila Bernardo \\ Universidade Cidade de São Paulo/ Parceiros da Educação. Doutora em Ensino de Ciências e Matemática. \\ ORCID: https://orcid.org/0000-0001-6482-4031. E-mail: priscila.martins@ unicid.edu.br.
}

NASCIMENTO, Julia de Cassia Pereira do

Núcleo Educacional Interação. Doutora em Ensino de Ciências e Matemática. ORCID: https://orcid.org/00000001-7209-2774. E-mail: juliacpn@terra.com.br.

CARVALHO, Jane Garcia de

Universidade Cruzeiro do Sul. Doutora em Ensino de Ciências e Matemática. https://orcid.org/0000-0003-32124772. E-mail: jane.carvalho@ cruzeirodosul.edu.br.

Resumo: Nesse artigo buscamos evidenciar e discutir como a proposta do Plano de Atividades Emergenciais implementada em uma disciplina de Estágio Curricular Supervisionado em Matemática nos Anos Finais do Ensino Fundamental, ofertada no curso de Licenciatura em Matemática na modalidade a distância de uma instituição de Ensino Superior privada na cidade de São Paulo, pode contribuir para a produção e mobilização dos conhecimentos das aprendizagens dos futuros professores. Para isso, o estudo foi norteado por uma abordagem de cunho qualitativo. Dentre os procedimentos adotados foram analisadas as narrativas dos futuros professores descritas nos relatórios de estágio (parte integrante da finalização do estágio), como uma maneira de refletir e relatar uma experiência, buscando o que essas narrativas revelam sobre o estágio a partir de atividades propostas. Dentre os resultados podemos destacar que, com as atividades emergenciais para realização de estágio, ficou claro que as Instituições de ensino devem promover formações que incorporem o desenvolvimento das competências, nos futuros professores, por meio de reflexão de uma possível prática profissional. Ou seja, os professores precisam ser submetidos a situações em que vivenciem as competências gerais e específicas de um documento norteador que visa alinhar documentos curriculares brasileiros, levando em conta as aprendizagens que os estudantes devem alcançar.

Palavras-chave: Estágio Curricular Supervisionado. Aprendizagens. Futuros Professores

\section{Knowledge and learning produced and mobilized by future teachers in an Internship course Possibilities in the Pandemic Context}

Abstract: In this article we seek to highlight and discuss how the proposal of the Emergency Activities Plan implemented in a discipline of Supervised Internship in Mathematics in the Final Years of Elementary School, offered in the Licentiate Degree in Mathematics in the distance modality of a private Higher Education institution in city of São Paulo, can contribute to the production and 




REVISTA BAIANA DE EDUCAÇÃO MATEMÁTICA

mobilization of knowledge of the learning of future teachers. For this, the study was guided by a qualitative approach. Among the adopted procedures, the narratives of future teachers described in the internship reports (an integral part of the internship completion) were analyzed as a way to reflect and report an experience, seeking what these narratives reveal about the internship from proposed activities. Among the results, we can highlight that, with the emergency activities for internship, it was clear that educational institutions should promote training that incorporate the development of skills, in future teachers, through reflection on a possible professional practice. In other words, teachers need to be subjected to situations in which they experience the general and specific competences of a guiding document that aims to align Brazilian curriculum documents, taking into account the learning that students must achieve.

Keywords: Supervised internship. Learnings. Future Teachers

\section{Conocimientos y aprendizajes producidos y movilizados por futuros profesores en un curso de prácticas Posibilidades en el contexto de una pandemia}

Resumen: En este artículo buscamos resaltar y discutir cómo la propuesta del Plan de Actividades de Emergencia implementado en una disciplina de Pasantía Supervisada en Matemáticas en los últimos Años de Bachillerato, ofrecida en la Licenciatura en Matemáticas en la modalidad a distancia de una Educación Superior privada. institución en la ciudad de São Paulo, puede contribuir a la producción y movilización del conocimiento del aprendizaje de los futuros docentes. Para ello, el estudio se guió por un enfoque cualitativo. Entre los procedimientos adoptados, se analizaron las narrativas de futuros docentes descritas en los informes de prácticas (parte integral de la finalización de la pasantía) como una forma de reflexionar y relatar una experiencia, buscando lo que estas narrativas revelan sobre la pasantía a partir de las actividades propuestas. Entre los resultados, podemos destacar que, con las actividades de emergencia para la pasantía, quedó claro que las instituciones educativas deben promover la formación que incorpore el desarrollo de habilidades, en los futuros docentes, a través de la reflexión sobre una posible práctica profesional. En otras palabras, los docentes necesitan ser sometidos a situaciones en las que experimentan las competencias generales y específicas de un documento rector que tiene como objetivo alinear los documentos curriculares brasileños, teniendo en cuenta los aprendizajes que deben alcanzar los estudiantes.

Palavras-Clave: Pasantía supervisada. Aprendizajes. Futuros profesores

\section{Introdução}

Em vários países, a formação dos professores apresenta-se como um grande desafio para as políticas educacionais. A preocupação com os professores, atores centrais na propagação do conhecimento, tornou-se mundial. Assim, medidas vêm sendo tomadas visando à formação mais sólida, em todos os níveis de ensino, e a viabilização de uma profissão mais atraente. Todavia, no Brasil, até então, não temos uma iniciativa, em âmbito nacional, robusta e considerável para adequar o currículo às demandas do ensino, que 


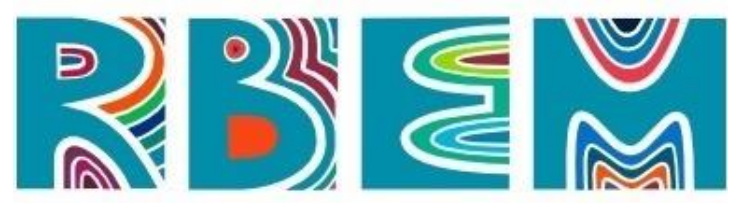

REVISTA BAIANA DE EDUCAÇÃO MATEMÁTICA

direcione a reestruturação da formação nas licenciaturas (GATTI, 2014).

De acordo com a autora em nosso país, nas instituições de Ensino Superior, não dispomos de um centro ou Instituto que concentre a formação de professores, em sua plenitude, com desenho próprio, como ocorre em outras profissões como a Medicina por exemplo. Em outros países, há centros de formação de professores, que incorporam todas as especialidades, voltadas a estudos, pesquisa e extensão correlatas à Educação, ação didática e às reflexões e teorias. Para a pesquisadora, as formações clássicas orientadas à preparação individual para o ofício docente têm se mostrado improdutivas, isto é, o modelo tradicional de formação inicial de professores apenas como propedêutica, de modo teórico desvinculado de experiências e conhecimentos adquiridos em campo prático, contrapõe-se às necessidades de metamorfose profissional que a contemporaneidade pleiteia.

Corroborando com a perspectiva de Gatti (2014) também nos questionamos: a formação fragmentada e reduzida, constatada nos currículos das Licenciaturas, é considerável para que os estagiários, como futuros professores, possam planejar, desenvolver, avaliar atividades de ensino na Educação Básica, encarando os aspectos de desenvolvimento integral e humano dos estudantes provenientes de contextos caracterizados, com preferências e incentivos diferenciados, comportamentos e hábitos conflitantes?

Atualmente, com o mundo enfrentando uma pandemia com o vírus COVID-19, vivemos no Brasil medidas restritivas na educação como a suspensão das atividades presenciais nas escolas e nas Universidades, o que exigiu ações emergenciais e adaptações em todas as áreas de conhecimentos.

A formação remota e emergencial que se consolidou historicamente no Brasil e no mundo, nos convida a refletir sobre como o cenário desencadeado pela pandemia, em tempo de isolamento social, pode afetar o processo de formação dos futuros professores de Matemática. Como está ocorrendo o processo de ensino e aprendizagem dos futuros professores de Matemática, a partir do momento atual de pandemia? O Estágio realizado a partir de atividades emergenciais pode prejudicar a relação entre a teoria e prática na formação inicial?

Pensando nessas questões, pretendemos nesse artigo, evidenciar e discutir como a proposta do Plano de Atividades Emergenciais implementada em uma disciplina de Estágio Curricular Supervisionado em Matemática nos Anos Finais do Ensino Fundamental, ofertada 


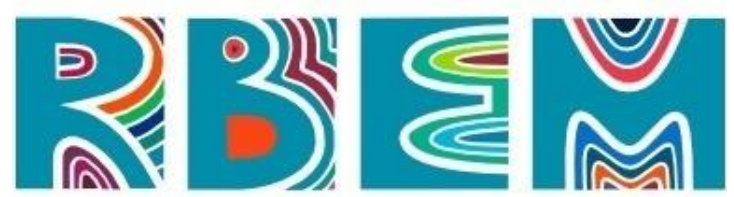

REVISTA BAIANA DE EDUCAÇ̄O MATEMÁTICA

no curso de Licenciatura em Matemática na modalidade EAD de uma instituição de Ensino Superior privada na cidade de São Paulo, pode contribuir para a produção e mobilização dos conhecimentos das aprendizagens dos futuros professores. Especificamente, buscamos averiguar se este processo de estágio mediante o Plano Emergencial se configura como possibilidade criativa. Ademais, também faremos uma análise das propostas das atividades emergenciais.

No que se refere a organização do referido estudo, a próxima seção apresenta a abordagem metodológica adotada e os procedimentos utilizados para análise dos dados. Em seguida, explanamos sobre o Estágio Curricular Supervisionado e o Ensino Remoto Emergencial e posteriormente, apresentamos o Estágio Curricular desenvolvido a partir de um Plano Emergencial. Depois, evidenciamos as análises e discussões sobre o estudo e por fim, trazemos algumas considerações referentes a pesquisa desenvolvida.

\section{Pressupostos metodológicos}

Ancorados no objetivo exposto, o referido estudo foi norteado por uma abordagem de natureza qualitativa. De acordo com Creswel (2010), a pesquisa qualitativa permite uma abordagem diferente da investigação acadêmica, isso porque emprega concepções filosóficas, estratégias de investigações, métodos distintos de coletas de dados, análises e interpretação dos dados.

Dentre os procedimentos adotados nesse estudo, foram analisadas as atividades que compunham o Plano Emergencial, buscando averiguar se estas assumem a perspectiva das novas DCN (BNC-Formação). Ademais, analisamos as narrativas dos futuros professores descritas nos relatórios de estágio (parte integrante da finalização do estágio), como uma maneira de refletir e relatar uma experiência, buscando o que essas narrativas revelam sobre o estágio a partir de atividades propostas. Freitas e Fiorentini (2007, p. 66) evidenciam que as análises narrativas "coletam descrições de eventos e de outros acontecimentos e geram uma narrativa como produto da pesquisa".

Nestas análises levamos em conta a visão e a interpretação dos estudantes em relação ao processo de estágio realizado a partir de atividades emergenciais propostas pelo Plano da Instituição. Além disso, destaca-se nestas análises a experiência vivenciada por uma das 


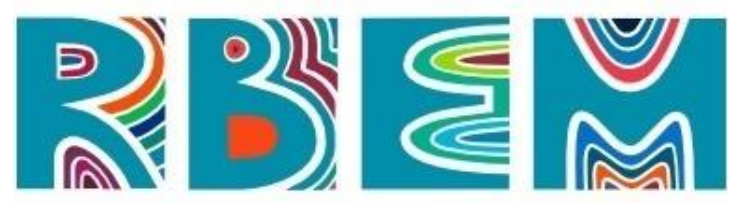

REVISTA BAIANA DE EDUCAÇÃO MATEMÁTICA

autoras deste artigo, que atuava como tutora formadora da disciplina, no processo de implementação do Plano Emergencial, na Instituição em que atuava.

O referido estudo também seguiu os pressupostos metodológicos da análise textual discursiva (MORAES, 2003), que se constitui de três etapas: Unitarização - exame dos materiais em seus detalhes, estabelecendo unidades de base; Categorização - estabelecimento de relações entre as unidades de base, para formação de categorias; Comunicação da compreensão emergente dos dois primeiros estágios, assim como de sua crítica e validação.

Contudo, a análise das atividades do Plano se deu a partir da primeira e terceira fase proposta pelo autor: a unitarização e a comunicação. Assim, procederemos à desconstrução dos relatos dos estudantes em fragmentos e depois elaboraremos um metatexto a partir do corpus de pesquisa, que no caso, foram os relatórios dos estudantes. Mas, reconhecendo que o foco deste estudo está no relato de uma experiência, apresentando características de uma narrativa como um discurso, denominaremos como análise metanarrativa. Esclarecido os procedimentos metodológicos passamos para a próxima seção.

\section{O Estágio Curricular Supervisionado}

No curso de formação de professores, o Estágio é um ato educativo desenvolvido no futuro campo profissional, visando à preparação para o ofício de ser professor - a constituição da Identidade e a mobilização de saberes e conhecimentos inerentes a área de conhecimento.

A transição de estudante a professor não é um processo momentâneo, sereno e concluso, mas sim, longo e inacabado, pois envolve inquietações e embates entre o que se idealiza e aquilo que, de fato, pode ser realizado na prática. Assim, o estágio se configura como fundamental nesse processo, pois é no convívio com os alunos da escola básica e seus professores, que o futuro professor mobiliza e produz conhecimentos, concebendo-se como profissional (FIORENTINI; CASTRO, 2003).

O Estágio Curricular Supervisionado retrata momentos da vida do futuro professor, pois os saberes da profissão são constituídos - aqueles que afloram da comunicação com a literatura educacional e o que se vê na prática da escola. Para Fiorentini e Castro (2003), o Estágio é uma aproximação experiencial de formação inicial que articula a ação, reflexão e 


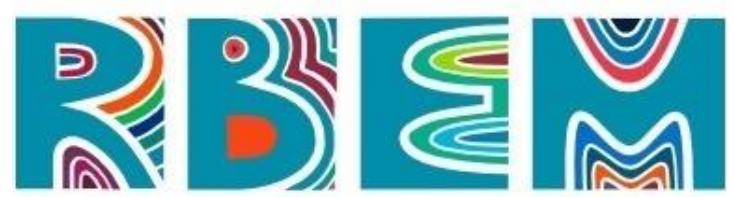

REVISTA BAIANA DE EDUCAÇ̄O MATEMÁTICA

investigação, nas quais os conhecimentos, percepções e valores inerentes a profissão são questionados e produz novos sentidos com relação com aquilo se estudou em sua trajetória estudantil e apreende a ser professor, ressignificando seus conhecimentos e práticas.

O estágio é parte integrante das matrizes curriculares dos cursos de licenciatura, portanto, considerado componente obrigatório para conclusão do curso. A lei 11.788, de 25 de setembro de 2008 dispõe, em seu artigo $2^{\circ}$, que o estágio poderá ser obrigatório (previsto na matriz curricular do curso e pré-requisito para a formação acadêmica) ou não-obrigatório (não previsto na matriz curricular, mas componente de complementação e formação profissional), conforme determinação das diretrizes curriculares da etapa, modalidade e área de ensino e do projeto pedagógico do curso.

Comumente, os estágios dos cursos de licenciatura ocorrem em dois momentos, que se articulam: 1. estudo teórico e conceitual a respeito do nível de ensino da disciplina de estágio e orientações acerca da realização e cumprimento do estágio e 2. Observação da prática de um professor e até mesmo regência em instituições escolares da Educação básica, de acordo com o nível de ensino.

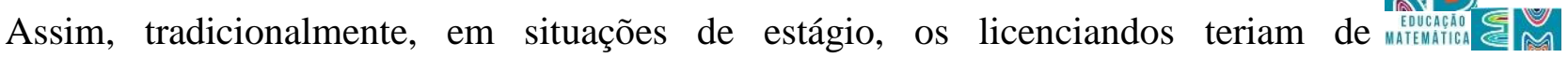
experienciar vivências da prática de um professor, em sala de aula. Mas, em decorrência da Pandemia COVID19 e pelo fato de a doença ser contagiosa e grave, a Organização Mundial de Saúde (OMS) decretou emergência de saúde pública.

Nesse contexto pandêmico, as aulas presenciais foram suspensas em todas as instituições de Ensino Básico e Superior no Brasil. Assim, visando a adequação dessa nova realidade, garantindo o distanciamento social e a oferta de ensino, as referidas instituições tiveram de recorrer ao Ensino Remoto Emergencial

O termo Remoto Emergencial está sendo muito discutido em função das experiências que estudantes e professores estão vivenciando e dessa relação com o Ensino a Distância. Especialistas têm defendido a não utilização do termo Educação a Distância quando se quer fazer a menção do ensino na pandemia.

De acordo com Hodges et al.(2020) o Ensino Remoto Emergencial - Emergency Remote Teaching - ERT, é uma opção temporária de ensino em razão da crise que estamos vivenciando e envolve o emprego de alternativas de ensino remotas para a instrução que, de 




REVISTA BAIANA DE EDUCAÇÃO MATEMÁTICA

outra maneira, seriam feitas presencialmente ou hibridas e que retornariam nesse modelo assim que a crise se findasse. Para os autores, o propósito central não é reinventar um ecossistema educacional robusto, mas, sim, propiciar acesso temporário a apoios instrucionais e educacionais de modo que sua implementação seja ágil e disponível no decorrer de uma emergência.

Na Portaria no 343, de 17 de março de 2020, o Ministério da Educação - MEC, dispõe sobre a substituição das aulas presenciais por aulas remotas durante a situação de pandemia do COVID-19. Assim, no seu artigo $1^{\circ}$, em caráter excepcional, a portaria autoriza a substituição das disciplinas presenciais por aulas que empregam meios e tecnologias digitais.

A portaria dispõe, ainda, que é de responsabilidade das instituições a determinação das disciplinas que poderão ser substituídas e a de providenciar recursos aos estudantes que permitam o acompanhamento dos conteúdos propostos e a realização de avaliações no período de pandemia. Contudo, em seu parágrafo $3^{\circ}$, foi vedada a substituição de práticas profissionais de estágios.

Soma-se a este panorama o fato de que uma das primeiras medidas tomadas por governos de todo o mundo no começo da pandemia de Covid-19, em março de 2020, foi o fechamento das escolas. O Brasil teve 267 dias de escolas fechadas até o fim de janeiro de

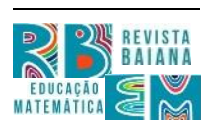
2021. Com isso, os estudantes das licenciaturas ficaram sem opções para realização dos estágios obrigatórios.

Esse impedimento culminou em muitas discussões e questionamentos: Como os estudantes, em situação de estágio, matriculados no último semestre, poderiam finalizar o curso de licenciatura, sendo que o estágio, é considerado por lei, como componente obrigatório para a conclusão de curso?

Nesse sentido, revogando a Portaria $n^{\circ} 343$ (BRASIL, 2020), o MEC publica a Portaria $\mathrm{n}^{\mathrm{o}} 544$ de 16 de junho de 2020, revogando as portarias anteriores que dispunham sobre o tema e, em caráter excepcional, autoriza a substituição dos estágios obrigatórios por atividades que empregam recursos digitais e outros meios de tecnologia da informação e da comunicação.

Com base nesta revogação, as instituições de ensino puderam dar continuidade ao processo de estágio de todos os estudantes matriculados nas disciplinas dos cursos por meio de Ambientes Virtuais de Aprendizagem e possibilidade de cômputo de atividades remotas 


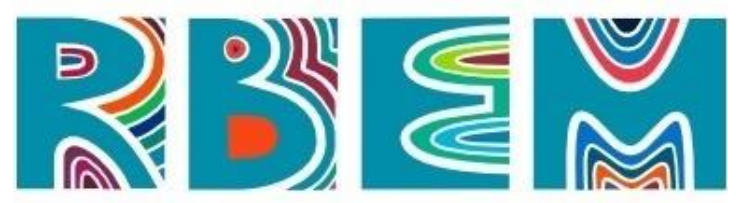

REVISTA BAIANA DE EDUCAÇÃO MATEMÁTICA

para o cumprimento da carga horária de estágio.

A aplicação da substituição de práticas profissionais ou de práticas que exijam laboratórios especializados, de que trata o $\S 3^{\circ}$, deve constar de planos de trabalhos específicos, aprovados, no âmbito institucional, pelos colegiados de cursos e apensados ao projeto pedagógico do curso (MEC, Port.544/2020,\$4")

À medida que nos deparamos com exemplos de planejamentos educacionais emergenciais, observamos situações que requerem uma solução criativa de problemas e a capacidade de se pensar fora dos padrões para conceber várias possibilidades que favoreçam o atendimento das novas demandas educacionais (HODGES ET AL. ,2020)

Compreendemos que, soluções criativas surgem a partir da colaboração entre os pares, de uma rede múltiplas percepções, linguagens e experiências. Na instituição em questão, para que as disciplinas de Estágios pudessem ser ofertadas, sem prejuízo aos estudantes, coordenadores, gestores, tutores e Pró-reitoria de Educação a Distância se empenharam em discutir e elaborar um Plano de Atividades Emergenciais que atendesse tanto as novas necessidades dos estudantes e demais envolvidos, como as determinações do MEC, dispostas na portaria 544 (BRASIL, 2020).

Assim, após a tramitação e ciência de instâncias superiores da Universidade, o Plano de atividades emergenciais foi implementado e os estudantes e tutores puderam dar continuidade e retomar as atividades de estágio.

\section{O Estágio Curricular Supervisionado em Matemática nos Anos Finais do Ensino Fundamental a partir de Atividades do Plano Emergencial}

Diante dessas concepções, nesse estudo abordaremos o Estágio obrigatório ofertado por meio de um Plano Emergencial, em uma Universidade particular da cidade de São Paulo, e acompanhado pela tutora da disciplina e como já citamos, uma das autoras desse estudo.

O Projeto Pedagógico do Curso de Licenciatura em Matemática na modalidade EAD da Universidade em questão, determina que o estágio é componente curricular obrigatório, seguindo as determinações legais. Desse modo, os futuros professores deverão cumprir 400 horas de Estágio, sendo 300 horas destinadas aos Anos Finais do Ensino Fundamental ( $6^{\circ}$ ao $9^{\circ}$ ano) e 150 horas no Ensino Médio ( $1^{\circ}$ ao $3^{\circ}$ ano). Nesse artigo focaremos no estágio 


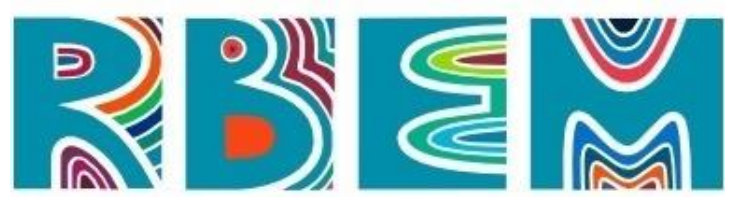

REVISTA BAIANA DE EDUCAÇÃO MATEMÁTICA

realizado a partir das observações e análises nos Anos Finais do Ensino Fundamental.

Conforme já destacamos, na impossibilidade da presença dos estudantes nas escolas de Educação Básica para cumprimento da carga-horária de estágio exigida para concluir assim essa etapa formativa, foi elaborado um Plano contendo uma sequência de Atividades Emergenciais, a serem cumpridas pelos estudantes, atribuindo a cada uma delas uma determinada quantidade de horas.

O Quadro a seguir sintetiza as propostas de atividades do Plano Emergencial e as respectivas quantidades de horas, que juntas totalizam as 150 horas de estágio exigidas neste semestre e presentes na Matriz Curricular do curso de Licenciatura em Matemática.

Quadro 1: Atividades do Plano Emergencial

\begin{tabular}{|c|c|c|}
\hline Atividade & Proposta & Quantidade de horas \\
\hline $\begin{array}{l}\text { Atividade BNCC } 1 \\
\text { Leitura, análise e produção de } \\
\text { texto sobre a competência geral } \\
\text { de número } 4 \text {. }\end{array}$ & $\begin{array}{l}\text { Nessa atividade, os estudantes fizeram a leitura da } \\
\text { quarta competência geral contida na BNCC e } \\
\text { depois analisaram essa competência fazendo uma } \\
\text { correlação com o nível de ensino da disciplina. Por } \\
\text { fim, teceram uma argumentação a favor do } \\
\text { desenvolvimento dessa competência para a } \\
\text { formação nos Anos Finais do Ensino Fundamental. }\end{array}$ & $40 \mathrm{~h}$ \\
\hline $\begin{array}{l}\text { Atividade BNCC } 2 \\
\text { Aplicação das competências aos } \\
\text { componentes curriculares da } \\
\text { educação básica }\end{array}$ & $\begin{array}{l}\text { Na atividade 2, os futuros professores escolheram } \\
\text { uma das competências gerais da educação básica da } \\
\text { BNCC (2017) para analisar, refletir e argumentar } \\
\text { como essa competência se articula com a } \\
\text { Matemática nos Anos Finais do Ensino } \\
\text { Fundamental. Nessa argumentação, eles também } \\
\text { deveriam incluir um Objeto de Conhecimento } \\
\text { correlato aos Anos Finais do Ensino Fundamental. }\end{array}$ & $40 \mathrm{~h}$ \\
\hline Plano de Aula & $\begin{array}{l}\text { Na terceira atividade, os estudantes elaboraram um } \\
\text { Plano de Aula, planejando e registrando os } \\
\text { aspectos importantes, tais como: objetivos, } \\
\text { conteúdos, duração, atividades, estratégias, } \\
\text { recursos. }\end{array}$ & $35 \mathrm{~h}$ \\
\hline Relatório Final de Estágio & $\begin{array}{l}\text { No relatório os estudantes organizaram as } \\
\text { informações sobre as atividades realizadas no } \\
\text { estágio a partir do Plano Emergencial, descrevendo } \\
\text { a razão de escolha de um determinado ano, objeto }\end{array}$ & \\
\hline
\end{tabular}




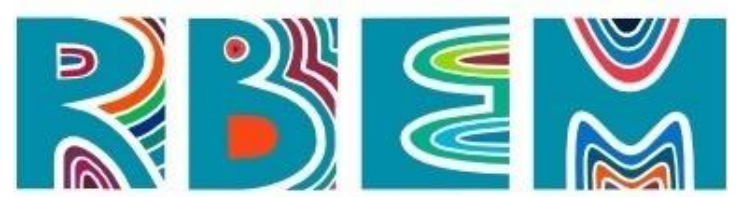

REVISTA BAIANA DE EDUCAÇÃO MATEMÁTICA

\begin{tabular}{|l|l||}
\hline de conhecimento e Unidade Temática para \\
desenvolver as atividades. Por fim, os estudantes \\
teceram reflexões críticas sobre esse processo, de \\
modo que eles pudessem expressar as \\
aprendizagens adquiridas e como essas \\
aprendizagens poderiam contribuir para o exercício \\
da profissão.
\end{tabular} \mid

Fonte: elaborado pelas autoras

Convém destacar que essa distribuição de horas se fez necessária, uma vez que é concedida dispensa de 50\% das horas para estudantes que já atuam como professores na Educação Básica (Resolução CNE/CP 2, de 19 de fevereiro de 2002, art.1º). Assim, esses estudantes que tinham a dispensa concedida poderiam optar por uma das atividades da BNCC - Base Nacional Comum Curricular - ou pelo Plano de Aula para complementarem as horas faltantes, pois a elaboração do relatório foi obrigatória.

As atividades 1 e 2 demandaram uma leitura atenta sobre a BNCC considerado um documento de caráter normativo que corresponde às demandas dos estudantes da Educação Básica preparando-os para o futuro. O documento determina um conjunto de aprendizagens essenciais que todos os estudantes devem desenvolver nos diferentes níveis de ensino da Educação Básica, de modo a assegurarem seus direitos de aprendizagem e desenvolvimento, em consonância com o que prescreve o Plano Nacional de Educação - PNE (Lei $13.005 / 2014)$.

Assim, ao desenvolverem as atividades, os estudantes puderam compreender as competências gerais da Educação Básica que consubstanciam, no campo pedagógico, os direitos de aprendizagem e desenvolvimento dos estudantes. Na atividade 1, a partir da leitura e análise crítica da competência 4, os estudantes fizeram uma correlação com a comunicação matemática, que, por sua vez, faz parte do Letramento Matemático, definido na própria BNCC como as competências e habilidades de raciocinar, representar, comunicar e argumentar, de maneira a promover a elaboração de conjecturas, a formulação e a resolução de problemas em múltiplos contextos, empregando conceitos, procedimentos, fatos e recursos matemáticos.

A proposta da atividade 1 é bem objetiva e pertinente, mas considerando que a comunicação pode surgir como conteúdo, objetivo e orientação metodológica (GUERREIRO; 


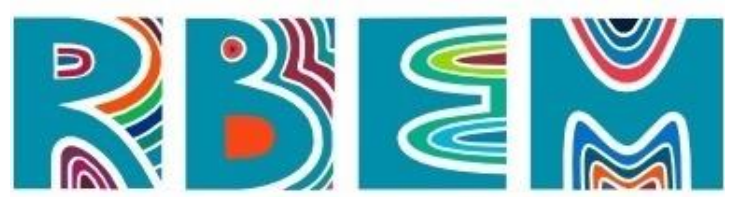

REVISTA BAIANA DE EDUCAÇÃO MATEMÁTICA

MENEZES, 2010), entendemos que seria interessante a inserção na atividade 1, de uma proposta que incentivasse os estudantes a escolherem uma unidade temática e um ano de escolaridade e analisassem a presença da comunicação nas habilidades presentes. Nesse sentido, os futuros professores poderiam ter clareza sobre os aspectos comunicativos que estão presentes nas habilidades ou objetivos de aprendizagem de um documento curricular.

Com relação a atividade 2, compreendemos ser importante que os estudantes conheçam e se apropriem das competências gerais da Educação Básica que estão presentes na BNCC, bem como que possam articulá-las com a sua área de conhecimento e nível de ensino, incluindo, ao menos, uma competência específica. No entanto, compreendemos que o caminho inverso seria interessante, ou seja, os estudantes fariam a leitura das competências gerais e escolheriam uma para tecer uma articulação com as competências específicas sobre essa área de conhecimento. E a partir disso, escolheriam um ano e uma unidade temática para relacionar essas competências com os Objetos de Conhecimento.

Outro aspecto que gostaríamos de destacar, é que nessa proposta de atividade, corre-se o risco de os estudantes escolherem a mesma competência da atividade 1 para produzir a atividade. Portanto, o ideal seria indicar na proposta que os estudantes deveriam escolher outra competência geral da Educação Básica para discorrer sobre a proposta.

Gostaríamos de evidenciar que as propostas de atividades 1 e 2 favorecem a apropriação do Conhecimento Curricular do Conteúdo (SHULMANN, 1986) que corresponde o domínio que engloba a compreensão dos documentos e materiais e dos programas que o professor emprega como recursos para o ofício.

$\mathrm{Na}$ atividade 3, os estudantes deveriam elaborar um Plano de Aula, guiando-se por alguns aspectos: nível de ensino, ano, componente curricular da Educação Básica, área prevista da BNCC, tema, objetivo, conteúdo, duração, atividades, estratégias, recursos e materiais necessários.

Consideramos esse tipo de atividade muito importante para que os futuros professores desenvolvam a competência de planejar já na formação inicial, isso porque, mesmo para um professor experiente, a sala de aula é permeada por muitos conflitos e marcada pela imprevisibilidade. Assim, o planejamento de uma aula é um processo cognitivo que requer a análise, reflexão e previsão de aula. Planejar parece bastante simples, mas é uma tarefa complexa de ser desenvolvida, sendo assim é preciso que os futuros professores pratiquem 


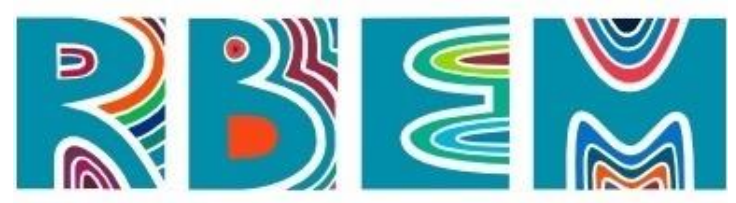

REVISTA BAIANA DE EDUCAÇÃO MATEMÁTICA

esse exercício de registrar o que se pretende fazer, como vão fazer e o que e como analisarão o que foi proposto, a fim de verificar se o objetivo foi contemplado ou não.

Ao analisarmos a proposta da atividade, observamos que os aspectos que os estudantes deveriam indicar no Plano de Aula são bem pertinentes, contudo, considerando que o documento orientador para a produção da atividade é a BNCC, algumas nomenclaturas do próprio documento deveriam ser utilizadas, como por exemplo, o item conteúdo da atividade refere-se ao Objeto de Conhecimento e a Habilidade prevista para a aula escolhida. Outro exemplo, o tema, a nomenclatura deveria ser: Unidade Temática.

Além disso, buscando estabelecer uma correlação com as demais atividades, acrescentaríamos como aspectos do Plano de Aula, o item - Indicadores de Avaliação, no qual os estudantes provavelmente estabeleceriam uma ligação com a atividade 1, que incorpora a Comunicação Matemática. Outro aspecto que poderia ser acrescentado é a organização da turma para potencializar discussões e aspectos comunicativos em sala de aula.

Compreendemos que, esse tipo de atividade fomenta a capacidade criativa dos futuros professores que ensinarão matemática. De acordo com Alencar (2016) esse tipo de capacidade refere-se pela abundância de ideias variadas produzidas sobre as mesmas temáticas - pela capacidade de alterar o raciocínio, por apresentar flexibilidade e detalhes de uma ideia. Portanto, ao elaborar um Plano de Aula, estes podem apresentar ideias, flexibilidade, originalidade e elaboração em suas produções, o que incentiva o seu desenvolvimento criativo.

No que se refere ao Relatório de Estágio sobre o Plano Emergencial, os estudantes puderam indicar todo o percurso realizado, tecendo reflexões críticas a respeito das atividades produzidas. Nesse sentido, consideramos importante que os estudantes sejam estimulados e orientados a revisitarem essas atividades, assim como que argumentem sobre a importância destas para a sua formação, as quais contribuem para aquisição de conhecimentos e competências importantes para o desenvolvimento pessoal e profissional nesta área de conhecimento.

Dito isso, passaremos adiante ao nosso processo analítico e conforme já dissemos, tomaremos como base a concepção e a interpretação dos estudantes sobre o processo de estágio realizado a partir de atividades emergenciais. Para isso, analisaremos os relatórios, pois compreendemos que nele estão as percepções dos estudantes a respeito das atividades 


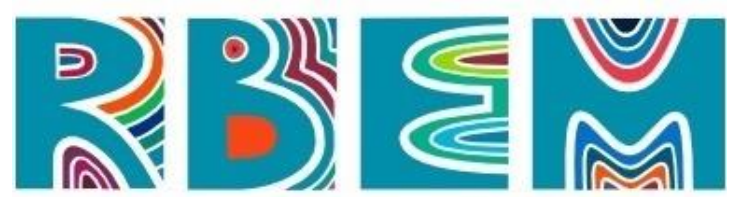

REVISTA BAIANA DE EDUCAÇ̄O MATEMÁTICA

produzidas.

\section{Análises e Discussões}

Neste item buscaremos analisar as percepções dos estudantes a respeito das atividades de Estágio no contexto do Plano Emergencial. Diante disso, tomaremos como referência o item 4 do relatório - que corresponde as reflexões críticas sobre o estágio. Assim, nesse item, buscaremos averiguar como as atividades organizadas no Plano Emergencial pode contribuir para a produção e mobilização dos conhecimentos das aprendizagens dos futuros professores que ensinarão Matemática.

Ao analisarmos as narrativas dos estudantes no relatório de estágio a partir do Plano Emergencial constatamos aspectos importantes que carecem de serem discutidos aqui.

As Diretrizes Curriculares Nacionais para a formação de professores $\mathrm{CNE} / \mathrm{CP}^{\circ}{ }^{\circ} 1$, de 2001 têm como arcabouço organizativo do currículo a produção de competências. Trata-se de um conhecimento que pode ser estimulado para tomar decisões em situações imprevisíveis. Em seu artigo $5^{\circ}$, é reiterado que a formação deve incorporar diferentes esferas do

conhecimento profissional do professor, mas que precisam ser interpretadas em competências específicas dessa área de conhecimento.

O Parecer CNE/CP n ${ }^{\circ} 22$, de 2019, chamado de Diretrizes Curriculares Nacionais para a Formação Inicial de Professores para a Educação Básica e Base Nacional Comum para a Formação Inicial de Professores da Educação Básica (BNC-Formação), preserva a carga horária dos cursos de formação inicial de professores para a Educação Básica, e anuncia que deve ser considerado nessa carga horária o desdobramento das competências profissionais em três dimensões, ou seja, conhecimento, prática e engajamento. No grupo II, as A DCN de Formação Inicial e Continuada de Professores prevê 1.600 horas para a aprendizagem dos conteúdos específicos das áreas, componentes, unidades temáticas e objetos de conhecimento da BNCC e para o domínio pedagógico desses conteúdos.

Entendemos que, para o estabelecimento dessas competências profissionais específicas, é preciso orientar os futuros professores na direção de uma formação mais sólida para o ensino de Matemática - o conhecimento curricular do conteúdo, a escolha de conteúdos, o conhecimento sobre modalidades pedagógicas e organizativas, a abordagem metodológica, a avaliação da aprendizagem, entre outros. 


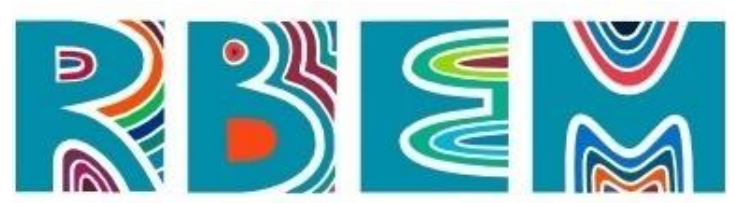

REVISTA BAIANA DE EDUCAÇÃO MATEMÁTICA

Desse modo, para formar um professor especialista em Matemática, é preciso garantir possibilidades formativas que incorporem os conhecimentos matemáticos, visando preparar os futuros professores para transformar os saberes construídos socialmente em aprendizagens, numa perspectiva que incorpore questões de natureza didática e curricular, mais especificamente incorporando as orientações da BNCC. Contudo, é necessário formar estes futuros professores para irem além daquilo que ensinarão nas variadas etapas da escolarização, ou seja, a articulação com outras áreas de conhecimento.

Assim, com a organização de atividades do Plano Emergencial, o conhecimento de natureza curricular que o futuro professor deve saber para o ensino de Matemática não ficou circunscrito às aulas de disciplinas teóricas, como a Didática da Matemática ou Metodologia do Ensino, possibilitando a redução da dicotomia entre teoria e prática.

O Estágio sob o viés de Atividades Emergenciais contribuiu para que os futuros professores pudessem conhecer um documento tão relevante, que é pautado em expectativas de aprendizagens, sendo reconhecido como uma referência nacional para a formulação dos currículos brasileiros.

Os professores futuros, ao conhecerem os conteúdos matemáticos do nível de ensino que devem ensinar, estarão atentos sobre aquilo que está em pauta em sua área de conhecimento, o que poderá refletir em sua prática futura com mais autonomia e criatividade.

As atividades correlatas a BNCC permitiu aos futuros professores uma análise mais aprofundada sobre as Competências Gerais da Educação Básica e específicas para o Ensino de Matemática, contribuindo para que estes pudessem articular essas competências com as Unidades Temáticas, Objetos de Conhecimento e Habilidades para o nível de ensino que atuarão.

Em suas narrativas, os futuros professores indicaram essa proximidade com o documento como um momento formativo muito significativo, o qual consideram um documento potencialmente rico e que esse estudo aprofundado trouxe muitas aprendizagens, reflexões, especialmente, em se tratando do conhecimento dos Objetos de Conhecimentos (conteúdos) e Habilidades prescritas para o futuro nível de atuação. Indicaram também o documento como base para planejar as aulas que ministrarão em campo prático. Alguns relatos a seguir ilustram tais constatações:

Estar em contato com a Base Nacional Comum Curricular, documento orientador da educação brasileira, analisando suas competências gerais e específicas, unidades 


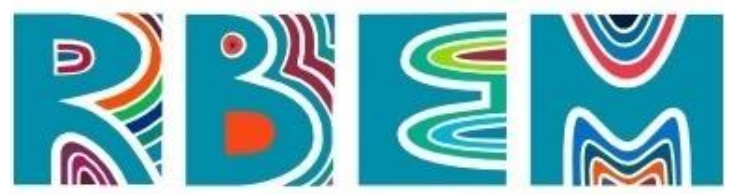

REVISTA BAIANA dE EDUCAÇÃO MATEMÁTICA

temáticas e objetos de conhecimento, contribuiu significativamente para minha formação, pois me permitiu compreender melhor os conteúdos e conceitos que devem ser trabalhados e consolidados durante os anos finais do Ensino Fundamental, de modo a garantir aos alunos o direito à aprendizagem, além de promover e garantir a eles o pleno desenvolvimento cognitivo, cultural e social. Assim, foi possível entender que a BNCC se constitui como uma ferramenta que fundamenta a qualidade da educação. (JOSÉ CARLOS, 2021)

Tenho certeza de que essa matéria vai ser a mais importante durante meu percurso na graduação, pois mostrou tudo sobre a BNCC e sua implementação, desde a sua introdução, que define o que é, a importância, suas competências, até as partes específicas para cada etapa e área da Educação Básica (IMYRA, 2021)

Na primeira parte deste trabalho tive a oportunidade de conhecer melhor a BNCC por meio da pesquisa, me aprimorando e fortalecendo minha formação acadêmica, ganhando respaldo teórico ao conhecer melhor como planejar os conteúdos programáticos propostos para as aulas, adquirindo uma boa variedade de bases para trabalhar com meus futuros alunos em sala de aula (LEANDRO, 2021)

Este caráter de estudo contínuo se dá pela importância dos temas abordados, como por exemplo as competências gerais da Base Nacional Comum Curricular (BNCC). É inegável riqueza deste documento, que permite orientar e dar todo um norte para o ensino e aprendizagem, destacando as habilidades e o desenvolvimento das potencialidades dos alunos, inserindo-os nas realidades atuais e buscando sempre tornar a sociedade mais justa, igualitária, democrática e consciente. É sob esta visão que o plano emergencial trouxe a possibilidade de conhecer com detalhes este magnífico documento e mais, trouxe a possibilidade de reflexão acercados seus temas, permitindo assim que os futuros professores conheçam a realidade do que é o essencial e os caminhos a serem trilhados para uma educação de excelência e igual para todos. (ANDERSON,2021)

Algo que pode soar como ingenuidade ou ignorância é o fato de eu nunca ter ouvido falar da BNCC - Base Nacional Comum Curricular, que era totalmente desconhecida para mim e junto dela outras siglas e temas começaram a fazer sentido: BNCC, PNLD, plano de aula, plano de curso, habilidades, como planejar o tempo da aula, entre outros (ANTONIO MANUEL, 2021).

Durante o período de estágio a partir deste plano emergencial, foi muito importante ler e compreender a BNCC. Através da leitura e a aplicação no que sugere na base nacional comum curricular, o processo de ensino de aprendizagem do estudante na educação básica se torna mais clara e objetiva. É notório que para se tornar um docente de qualidade e profissional, ele deve conhecer bem esse documento normativo, para garantir a qualidade do ensino (FREDSON,2021)

Outro aspecto que gostaríamos de destacar nesse texto e que contribuiu para as aprendizagens dos futuros professores diz respeito a análise da Competência Geral de Educação Básica de número 4 que corresponde a capacidade de — Utilizar diferentes linguagens - verbal (oral ou visual-motora, como Libras, e escrita), corporal, visual, sonora e digital -, bem como conhecimentos das linguagens artística, matemática e científica, para se expressar e partilhar informações, experiências, ideias e sentimentos em diferentes contextos e 


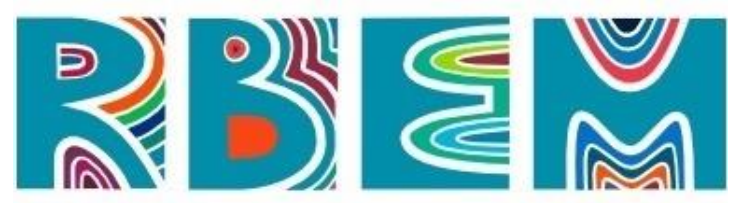

REVISTA BAIANA DE EDUCAÇÃO MATEMÁTICA

produzir sentidos que levem ao entendimento mútuo.

Trata-se de uma competência também relacionada ao Letramento Matemático, especialmente a Comunicação.

Convém destacar que, a comunicação, durante muito tempo, esteve relacionada a Língua Portuguesa e outras áreas de conhecimento, o que não incluía a área de Matemática. Contudo, atualmente, pesquisas revelam que, em todos os níveis de ensino, os professores necessitam incentivar o espírito questionador dos estudantes, na direção de torná-los pensantes para que estes possam comunicar ideias matematicamente, seja oralmente, por desenho ou registros escritos, pois a comunicação na Matemática contempla a linguagem natural e a simbologia própria da área. Assim, a oralidade permite possibilidades de interação entre os estudantes, entre eles e o professor e a comunicação escrita permite uma sistematização de ideias e reflexão sobre as mesmas.

Nesse sentido, direcionar os futuros professores na análise dessa competência tão importante, pode contribuir para que este assuma futuramente um papel de potencial intervenção em sala de aula, pois é mediante a comunicação oral que se realiza o processo de negociação de significados matemáticos entre o professor e os estudantes, entre os estudantes e entre os estudantes e toda comunidade educativa e por meio da comunicação escrita que se permite uma sistematização de ideias, reflexão sobre essas ideias e o argumentar matematicamente. Sem dúvidas, uma intervenção eficaz contribui para uma melhor e mais ágil compreensão de conceitos matemáticos e a melhoria da qualidade de ensino.

Compreendemos que, para que o futuro professor possa romper com a concepção prevalecente de que os estudantes aprendem matemática a partir de memorização de fórmulas e uma lista exaustiva de exercícios, é importante que o trabalho com a comunicação esteja sempre presente, para que o ensino da Matemática possa, de fato, ocorrer na sala de aula.

Os futuros professores, ao analisarem essa competência relacionada à comunicação, puderam refletir sobre quais aspectos comunicativos são importantes para serem empregados em sala de aula, dando pistas para que eles possam compreender os modos dos pensamentos de seus futuros alunos. Os relatos, a seguir, ilustram essa constatação:

Estudando as competências da BCNN foi possível entender que diversas formas de introdução de um determinado assunto na matemática, em sala de aula, são possíveis. Empregando a linguagem escrita, oral até mesmo artística, usando 


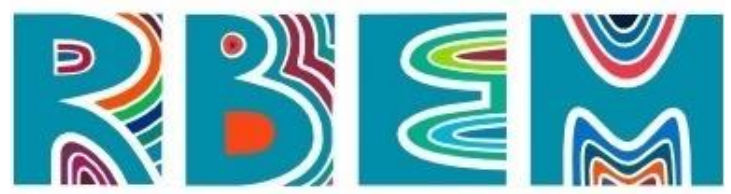

REVISTA BAIANA DE EDUCAÇÃO MATEMÁTICA

pinturas e artes para identificar a geometria, por exemplo. Usar a criatividade e levar diferentes linguagens para sala de aula é fundamental para interação AlunoProfessor, a fim de que o conhecimento aconteça para ambos e de forma Inspiradora (ABEL, 2021)

$\mathrm{Na}$ atividade 1 pude refletir sobre que tipo de aula gostaria de proporcionar aos meus futuros alunos, quais os recursos de comunicação poderei utilizar, quais recursos visuais serão bons o bastante para que a matemática deixe de ser olhada com medo e passe a ser algo descomplicado, desafiador imaginar como definir quais recursos utilizar quando as novidades surgem de forma tão rápida (ANTONIO MANUEL, 2021)

Correlacionando com a minha futura formação, agregou muito conhecimento, pois percebi que o aluno no decorrer da sua formação deverá aprender a se comunicar e que mesma poderá ser realizada em várias linguagens como: visual, libras e outras. Levando isso pra prática docente, posso usar essa competência na forma de passar o conteúdo, pois cada aluno tem uma forma que consegue aprender melhor. Então, é necessário, além da linguagem oral, acrescentar outras formas de linguagem para que todos consigam compreender (KELLY, 2021)

A competência geral 4 da BNCC que foi estudada durante o estágio se refere a utilização de diferentes linguagens para o entendimento mútuo. É a competência da comunicação, da promoção da escuta e do diálogo. De fato, sem uma boa comunicação entre alunos e professores abordagem e compreensão dos temas propostos fica prejudicada, bem como a dinâmica de diálogo entre todos. Assim foi possível refletir sobre como tornar a aula um espaço produtivo e inclusivo na emissão e recepção de informações. Citar exemplos e problemas que se referem ao cotidiano dos alunos é uma forma de despertar seu interesse, bem como a maneira de fazer isso. Atualmente, as tecnologias se tornaram uma grande ferramenta no desenvolvimento de atividades de exemplificação e experimentação. No que se refere aos alunos, esta competência deve promover a capacidade de comunicação dos alunos na apresentação, justificativas e sustentação de suas ideias e raciocínio. $\mathrm{Na}$ área de matemática é uma competência que pode ser muito explorada na resolução de problemas (LAIS, 2021)

A competência 4, a qual foi o tema central da atividade 1, esta realizada aos processos de comunicação. A comunicação dentro da Matemática é essencial, pois as ciências exatas de forma geral são muitas vezes baseadas somente na conceptualização expositiva dos diferentes conceitos científicos e da explicação de fórmulas. Trazer essa percepção da comunicação para dentro da Matemática é importante para permitir ao aluno o contato através de outras formas de linguagens com esses conteúdos, desenvolvendo uma percepção pratica da matemática no seu dia a dia, bem como ampliando suas possibilidades de comunicação e transmissão de conhecimento para como outros. (LEONARDO, 2021)

Análise da competência geral de número 4, que fala sobre a comunicação, e mostra o quanto é importante ajudar futuro egresso na utilização de diversas formas de linguagem. Essa competência proporciona ao aluno o desenvolvimento de ferramentas que o ajudarão a melhorar sua forma de comunicação perante a sociedade, e assim promover uma sociedade mais propensa ao conhecimento e ao diálogo, e que isto aconteça deforma respeitosa e com entendimento mútuo. Além disso o egresso que desenvolver essa habilidade será capaz de se expressar com diferentes linguagens, conseguindo assim, informar com clareza, falar sobre suas experiências, ideias e sentimentos, de forma que seja entendido pelos que o estão escutando (PAULA) 


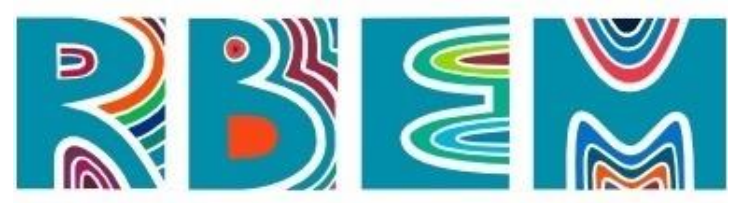

A atividade envolvendo a produção de um Plano de Aula foi imprescindível para a aquisição do conhecimento curricular do conteúdo, por parte dos futuros professores, uma vez que eles tiveram que articular as competências- básicas e específicas para o Ensino de Matemática analisadas com as Habilidades e Objetos de Conhecimentos da Unidade Temática escolhida dessa área de conhecimento. Assim, ao propor um Plano de Aula, os professores mobilizaram os conhecimentos adquiridos nas primeiras atividades. Um bom planejamento não teria sido possível se os estudantes não tivessem feito esse exercício com a BNCC. Nesse movimento, eles tiveram de indicar muitos aspectos que envolvem também a gestão de sala de aula, que mesmo para um professor mais experiente, é permeada por conflitos e questionamentos, dado que a imprevisibilidade é um aspecto muito presente em sala de aula e requer criatividade, reflexões e outros conhecimentos além do curricular, ou seja, o conhecimento do conteúdo e do ensino (relação entre os conteúdos a serem ensinados e o modo a ensiná-los), o conhecimento dos estudantes e do contexto.

Desse modo, ao elaborar um Plano de Aula, os futuros professores puderam adquirir conhecimentos primordiais para o Ensino de Matemática, o que pode indicar segurança em futura prática profissional, frente as situações de ensino.

De acordo com as narrativas dos futuros professores, produzir um Plano de Aula foi uma proposta bastante produtiva e que gerou contentamento e aprendizagens significativas, contribuindo para o entendimento de como deve ocorrer o desenvolvimento de uma aula e quais recursos devem ser empregados. Ademais, o conhecimento sobre a BNCC permitiu que os futuros professores pudessem compreender a importância das competências nesse processo e elaborar o Plano de Aula com mais facilidade, indicando as Habilidades e Objetos de Conhecimento que a atividade deve contemplar. As narrativas adiante ilustram essa constatação:

O desenvolvimento do plano de aula foi a terceira atividade proposta, onde foi realizado a escolha de um tema, e o desenvolvimento de uma aula a partir do mesmo. Atividade esta muito importante, pois nos faz refletir sobre como deve ocorrer o desenvolvimento da aula, e as ferramentas que devem ser utilizadas para que os alunos tenham interesse e consigam aprender o conteúdo e desenvolver as habilidades necessárias. O conhecimento da BNCC, a análise das competências gerais, e o desenvolvimento do plano de aula, contribuíram para minha formação como futura professora, e me ajudaram a entender quais são os objetivos a serem alcançados e a importância do desenvolvimento das competências na formação dos alunos, e o impacto positivo que esses ensinamentos devem trazer para a sociedade. (PAULA, 2021) 


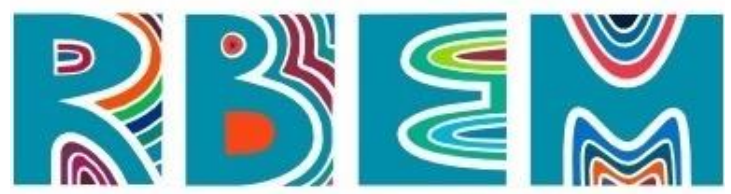

A elaboração de um plano de aula também representou uma experiência enriquecedora e bastante produtiva, permitindo entender algumas metodologias de ensino, práticas pedagógicas. Com a elaboração do plano de aula, percebe-se que mesmo funciona como um guia, orientando o professor sobre os conceitos a serem abordados na aula, os objetivos que pretende alcançar, ampliando o horizonte docente acerca de opções criativas que possam contribuir para que os objetivos propostos sejam alcançados, despertando o interesse e a curiosidade do aluno para o tema trabalhado (JÓSE CARLOS, 2021)

A vivência em sala de aula trás situações inesperadas e que vão além do plano de aula programado. Durante esse período consegue ter melhores caminhos para solução de acontecimentos, seja entre alunos, em caráter de trabalho em equipe, as divergências entre turmas, pois todos os alunos são diferentes e o que se utiliza em uma turma, não necessariamente pode ser aplicada em outra, essa maneira de se reinventar para conseguir transmitir o conhecimento é muito satisfatório como profissional licenciado em Matemática (AIRLIS, 2021)

Outro ponto fundamental trabalhado no plano emergencial e de grande importância para a prática docente é a elaboração de um plano de aula. Nesta prática foi possível inserir-se em todo o planejamento de uma aula, buscando inserir o assunto na realidade cotidiana dos alunos, buscar diferentes métodos de transmitir o conhecimento, propor atividades que impulsionam e motivamos estudantes ao estudo de determinada matéria. Por em prática todo este planejamento permite um sentimento de zelo pelo aprendizado, sempre buscando organizar formas de transmitir o conhecimento de modo a todos compreenderem, a refletir as diferenças de aprendizado de cada aluno onde os modos de ensino têm de ser de acordo com a realidade de cada um. Eis aí um ponto de extremo valor no qual o exercício da elaboração do plano de aula trouxe para futura atuação, a possibilidade de transportar-se para o ser do aluno, de enxergar com cuidado e dedicação para o "o quê" e "o como" o estudante irá aprender (ANDERSON, 2021)

Ao desenvolver o plano de aula para a área de matemática como uma das atividades do estágio, foi possível estruturar todo o processo de como levar para a sala de aula temas compatíveis com as competências gerais e específicas determinadas na BNCC, atendendo o conteúdo programático de forma que desperte o interesse, o raciocínio e criatividade dos alunos (LAIS, 2021)

Os planos de ensino são essenciais pois deixa claro quais são os objetivos da aula, como estes objetivos serão atingidos e em quanto tempo. O plano de ensino é guia capaz de orientar o docente sobre seus objetivos e abre um leque de opções criativas a fim de alcançá-los. A elaboração de planos de aula põe o professor em uma posição de elaboração e reflexão sobre qual é o conhecimento que ele deve proporcionar ao aluno e das melhores formas, linguagem e ferramentas que podem ser utilizados para alcançar os objetivos. Além da organização para o professor que os planos de ensino trazem para o dia a dia da prática docente, estes permitem também insights para integração com os diferentes itinerários formativos. No plano de aula, foi proposto uma série de aulas com a temática de Gráficos, os quais são meios de informações e comunicação utilizadas pelas diferentes mídias diariamente, utilizando muitas vezes conceitos equivocados e com informações que podem enganar um leitor menos atento (LEONARDO, 2021)

Os futuros professores ainda destacaram algumas aprendizagens neste processo. 


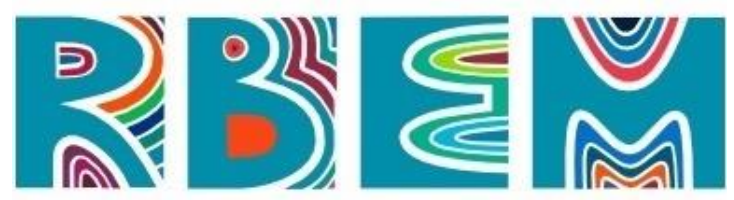

REVISTA BAIANA DE EDUCAÇÃO MATEMÁTICA

Mesmo que o estágio não tenha sido presencial, não invalidou esse processo formativo que visa articular teoria e prática. Vejamos algumas narrativas a esse respeito:

Será que foi possível aprender alguma coisa? Com toda a certeza! Cada atividade feita trouxe uma reflexão ainda maior sobre a prática, novos olhares para situações que podem ocorrer na sala de aula antes mesmo de vivenciá-las. As atividades possibilitaram o conhecimento sistêmico da BNCC, e ficou evidente, ainda sem praticar o que está no documento, que o caminho apontado, o desenvolvimento de habilidades e competências é, sem dúvida o caminho a seguir. E como alcançar cada uma das habilidades? Através do Plano de Aula (LEIDIANE, 2021)

Mesmo não tendo feito o estágio presencialmente, a realização do estágio remoto alcançou seu proposito que é capacitar o profissional que irá iniciar acarreia docente, os estudos dos documentos- BNCC, a montagem de um plano. Foram um exercício das atividades que cabe ao profissional da educação, a sala de aula é o campo principal de trabalho é onde estão as peças principais do processo de ensino e aprendizagem, contudo antes de realizar uma aula o professor deve tê-la bem planeja considerando as mais variadas possibilidades de mudança, ou seja, conforme o andamento da turma o professor precisa estar preparado para ir além com o conteúdo ou adaptá-lo para realidade de seu público (ANA PAULA, 2021)

Com essas atividades emergenciais para realização de estágio, ficou claro que as Instituições de ensino devem promover formações que incorporem o desenvolvimento das competências, nos futuros professores, por meio de reflexão de uma possível prática profissional. Ou seja, os professores precisam ser submetidos a situações em que vivenciem as competências gerais e específicas de um documento norteador que visa alinhar documentos curriculares brasileiros, levando em conta as aprendizagens que os estudantes devem alcançar.

\section{Considerações Finais}

Como professoras formadoras que somos, o advento da pandemia e a possibilidade de substituir a realização do estágio obrigatório nas escolas por atividades a serem desenvolvidas remotamente por meios digitais, trouxeram-nos algumas reflexões.

Porém, acreditamos que se a prática é parte importante da formação de professores, o conhecimento e reflexão sobre todo o processo é igualmente imprescindível. Os estágios têm um grande potencial formativo, nas diferentes instâncias de sua realização, ou seja, na escola, nas leituras, reflexões e ressignificações dos conhecimentos e conceitos adquiridos.

Este artigo nos propiciou observações que na prática usual da realização de estágios presenciais talvez não nos fosse possível observar. Isto porque no estágio realizado nas escolas os estudantes focam suas observações na prática do professor, nas atividades desenvolvidas e pouca ou nenhuma atenção é dada aos documentos norteadores desta prática.

Com as atividades emergenciais para realização de estágio, ficou claro que as 


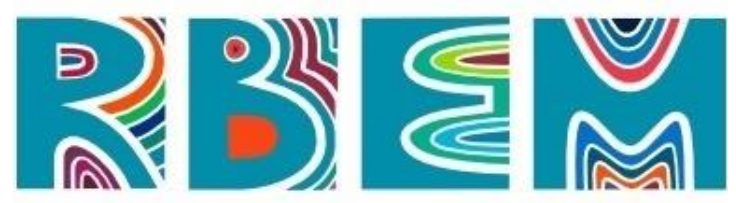

REVISTA BAIANA DE EDUCAÇÃO MATEMÁTICA

Instituições de ensino devem promover formações que incorporem o desenvolvimento das competências, nos futuros professores, por meio de reflexão de uma possível prática profissional. Ou seja, os professores precisam ser submetidos a situações em que vivenciem as competências gerais e específicas de um documento norteador que visa alinhar documentos curriculares brasileiros, levando em conta as aprendizagens que os estudantes devem alcançar.

A formação inicial, comumente, deixa lacunas para o exercício da prática docente e a BNCC apresenta transformações relevantes na prática de ensino. Com essas atividades, os futuros professores perpassaram por etapas importantes no estágio: a reflexão, ação, conhecimento e criatividade.

Ao escolhermos como foco de nossas análises o item do relatório que corresponde as reflexões críticas sobre o estágio, entendíamos que neste espaço o estudante pode tecer críticas construtivas, elogios, propostas e sugestões para melhoria da prática e maior aprendizagem dos alunos.

Além disso, ao tecer suas reflexões sobre o estágio e sobre as atividades propostas no Plano Emergencial, o estudante nos mostraria quais foram as contribuições deste momento de estágio para sua formação, além de apresentar propostas e sugestões sobre este momento diferenciado da realização dos estágios.

Na reflexão eles conheceram e se apropriaram das competências básicas e específicas, Unidades Temáticas, Habilidades e Objetos de Conhecimentos e compreenderam a importância da Comunicação Matemática nesse processo.

Com a ação, conhecimento e criatividade eles puderam repensar sobre aprendizagens adquiridas, além de utilizarem sua criatividade e conhecimento para produzir um Plano de Aula.

A valorização desses conhecimentos das primeiras atividades é determinante para o planejamento de uma aula, colocando esses professores futuros como protagonistas de seu próprio processo de desenvolvimento profissional. É inegável o quanto é preciso pensar em formações alinhadas à BNCC.

Voltando à nossa indagação inicial de como está ocorrendo o processo de ensino e aprendizagem dos futuros professores de Matemática, a partir do momento atual de pandemia e, se o Estágio realizado a partir de atividades emergenciais pode prejudicar a relação entre a teoria e prática na formação inicial, entendemos que nossas observações e análises nos 


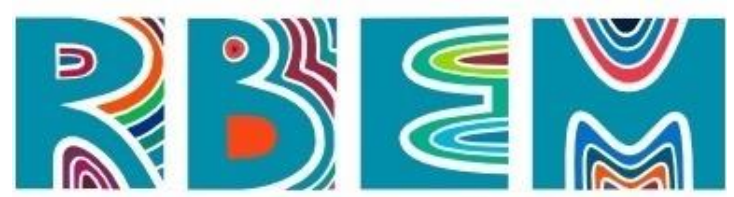

mostraram alguns pontos a destacar.

As falas dos alunos acerca das atividades propostas para a realização do estágio indicam a importância do direcionamento dado pela instituição na elaboração das mesmas, privilegiando as recentes mudanças trazidas pela $\mathrm{BNC}$, assim como os conhecimentos necessários à formação para ensinar Matemática na Educação Básica.

Isto nos mostra que, embora com a pandemia e a impossibilidade de estar presencialmente nas escolas, os alunos entenderam que a observação na sala de aula é apenas um dos momentos do estágio, que se complementa com leituras, atualizações e conhecimento sobre a atual situação da educação em termos de leis e normas. Muitos alunos confessam desconhecer o que seria a BNCC.

Chamou nossa atenção também as contribuições dos alunos sobre a elaboração de um Plano de Aula. Todos destacaram a importância deste documento para sua futura prática docente. Embora, conforme já destacamos, entendemos que os aspectos a serem indicados no Plano de Aula proposto pelo Plano Emergencial sejam relevantes, como o documento indicado para a produção da atividade é a BNCC, deveriam ser utilizadas nomenclaturas do próprio documento, como por exemplo, o item tema deveria ser substituído pela nomenclatura Unidade Temática.

A pandemia mundial trouxe um novo pensar sobre a educação. No Brasil, a realização dos estágios por meio remoto nos fez repensar sobre o que é importante destacar nas atividades e reflexões propostas aos alunos.

Mas, é certo que alunos, professores e formadores devem estar sempre abertos a discutir novas teorias, renovar suas ideias e ações para que possam acolher o que de novo se apresenta, aprimorando cada vez mais o conhecimento, aprendizagem e a formação dos professores que ensinam matemática.

\section{Referências}

ALENCAR, Eunice Maria Lima Soriano de. Como desenvolver o potencial criador: um guia para a liberação da criatividade em sala de aula. Petrópolis: Vozes, 1990.

BRASIL. Conselho Nacional de Educação. Conselho Pleno. Resolução CNE/CP 1, de 18 de fevereiro de 2002. Institui Diretrizes Curriculares Nacionais para a Formação de Professores de Educação Básica, em nível superior, curso de licenciatura, graduação plena. Disponível em 


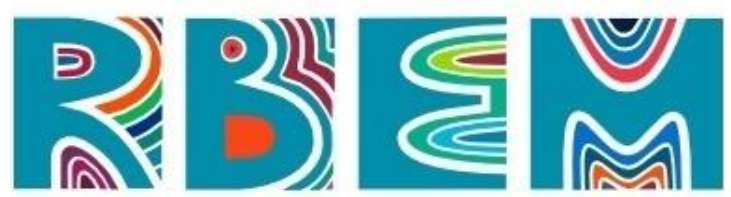

REVISTA BAIANA DE EDUCAÇÃO MATEMÁTICA

http://portal.mec.gov.br/index.php?option=com_docman\&view=download\&alias=159261 rcp001-02\&category_slug=outubro-2020-pdf\&Itemid=30192. Acesso em 18 jun.2021

BRASIL. Conselho Nacional de Educação. Conselho Pleno. Resolução CNE/CP 2, de 19 de fevereiro de 2002. Institui a duração e a carga horária dos cursos de licenciatura, de graduação plena, de formação de professores da Educação Básica em nível superior. Disponível em http://portal.mec.gov.br/index.php?option=com_docman\&view=download\&alias=159251rcp002-02\&category_slug=outubro-2020-pdf\&Itemid=30192. Acesso em 18 jun.2021

BRASIL. Conselho Nacional de Educação. Conselho Pleno. Parecer $C N E / C P n^{\circ} 22$, de 7 de novembro de 2019. Diretrizes Curriculares Nacionais para a Formação Inicial de Professores para a Educação Básica e Base Nacional Comum para a Formação Inicial de Professores da Educação Básica (BNC-Formação). Disponível em http://portal.mec.gov.br/index.php?option=com_docman\&view=download\&alias=133091pcp022-19-3\&category_slug=dezembro-2019-pdf\&Itemid=30192. Acesso em 18 jun.2021

BRASIL. Lei $n .11788$ de 25 de setembro de 2008. Dispõe sobre o estágio dos estudantes. Disponível em http://www.planalto.gov.br/ccivil_03/_ato2007-2010/2008/lei/111788.htm. Acesso em 10 mai.2021

BRASIL. Lei $n^{o}$ 13.005, de 25 de junho de 2014. Aprova o Plano Nacional de Educação PNE e dá outras providências. Diário Oficial da União, 26 jun. 2014. Disponível em http://www.planalto.gov.br/ccivil_03/_ato2011-2014/2014/lei/113005.htm. Acesso em Acesso em 21 jun. 2021

BRASIL. Ministério da Educação. Base Nacional Comum Curricular. Brasília, 2018. Disponível em http://basenacionalcomum.mec.gov.br/images/BNCC_EI_EF_110518_versaofinal_site.pdf. Acesso em 21 jun. 2021

BRASIL. Portaria $n^{\circ} 343$, de 17 de março de 2020. Dispõe sobre a substituição das aulas presenciais por aulas em meios digitais, enquanto durar a situação de pandemia do Novo Coronavírus- COVID-19. Diário Oficial da União. Brasília, DF, 18 mar. 2020. Disponível em www.in.gov.br/en/web/dou/-/portaria-n-343-de-17-de-marco-de-2020-248564376. Acesso em 19 mai. 2021.

BRASIL. MEC. Portaria $n^{\circ}$ 544, de 16 de junho de 2020. Dispõe sobre a substituição das aulas presenciais por aulas em meios digitais, enquanto durar a situação de pandemia do Novo Coronavírus - Covid-19, e revoga as Portarias MEC no 343, de 17 de março de 2020, n $^{\circ} 345$, de 19 de março de 2020, e $\mathrm{n}^{\circ} 473$, de 12 de maio de 2020. Disponível em http://www.in.gov.br/web/dou/-/portaria-n-544-de-16-de-junho-de-2020-261924872. Acesso em 21 jun. 2021.

CRESWELL, John. W. Projeto de pesquisa: métodos qualitativo, quantitativo e misto. 3. ed. Porto Alegre: Artmed, 2010. 


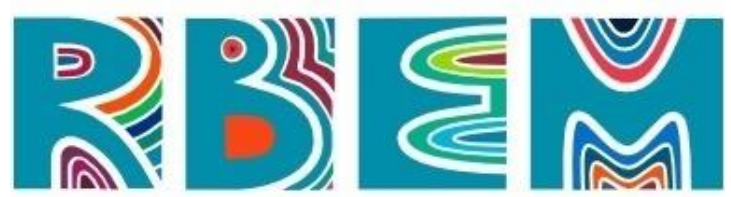

REVISTA BAIANA DE EDUCAÇĀO MATEMÁTICA

FIORENTINI, Dario; CASTRO, Franciana Carneiro. Tornando-se professores de matemática: O caso de Allan em Prática de Ensino e Estágio Supervisionado. IN: FIORENTINI, Dario (Org). Formação de professores de Matemática: explorando novos caminhos com outros olhares. Campinas, SP; Mercado das Letras, 2003, p. 121-156.

FREITAS, Maria Teresa Menezes ; FIORENTINI, Dario. As possibilidades formativas e investigativas da narrativa em educação matemática. USF, Revista Horizontes, v. 25, n. 1, p. 63-71, jan./jun. 2007. Disponível em

http://lyceumonline.usf.edu.br/webp/portalUSF/itatiba/mestrado/educacao/uploadAddress/Ho rizontes_25_1_06[11067].pdf . Acesso em 15 jun.2021

GATTI, Bernardete A. (2014). A formação inicial de professores para a educação básica: as licenciaturas. Revista USP, (100), 33-46. Disponível em https://doi.org/10.11606/issn.23169036.v0i100p33-46. Acesso em 10 jun.2021

GUERREIRO, Antonio \& MENEZES, Luís. (2010). Comunicação matemática: na busca de um entendimento comum. In H Gomes, L. Menezes e I. Cabrita (Eds.). XXI SIEM (pp. 137143). Lisboa: APM. Disponível em

https://repositorio.ipv.pt/bitstream/10400.19/1168/1/Guerreiro\%26Menezes.pdf. Acesso em 20 jun. 2021

HODGES, Charles; MOORE, Stephanie; LOCKEE, Barb; TRUST,Torrey; BOND, Aaron. The Difference between emergency remote teaching and online learning. Educause Review, 2020. Disponível em https://er.educause.edu/articles/2020/3/the-difference-betweenemergency-remote-teaching-and-online-learning\#fn7. Acesso em 10 set. 2020.

MARTINS, Priscila Bernardo; CURI, Edda. Estágio Curricular Supervisionado: uma retrospectiva histórica na legislação brasileira (Supervised Curricular Internship: a historical retrospective on the Brazilian legislation). FAI-UFSCar. Revista Eletrônica de Educação, v. 13, n. 2, p. 689-701, maio/ago. 2019. Disponível em https://dx.doi.org/10.14244/198271992471. Acesso em 10 jun.2021

MORAES, Roque. Uma tempestade de luz: a compreensão possibilitada pela análise textual discursiva. Ciência \& Educação: Bauru, SP, v. 9, n. 2, p. 191-210, 2003. Disponível em https://www.scielo.br/j/ciedu/a/SJKF5m97DHykhL5pM5tXzdj/?format=pdf\&lang=pt.

Acesso em 25 jun.2021

SHULMAN, Lee S. Those Who Understand: Knowledge Growth in Teaching. Educational Researcher. v.15, n.2. fev. 1986, pp.4-14. Disponível em https://depts.washington.edu/comgrnd/ccli/papers/shulman_ThoseWhoUnderstandKnowledge GrowthTeaching_1986-jy.pdf. Acesso em 30 mai.2021

Artigo submetido em: 29/06/2021

Artigo aceito em: 20/10/2021 